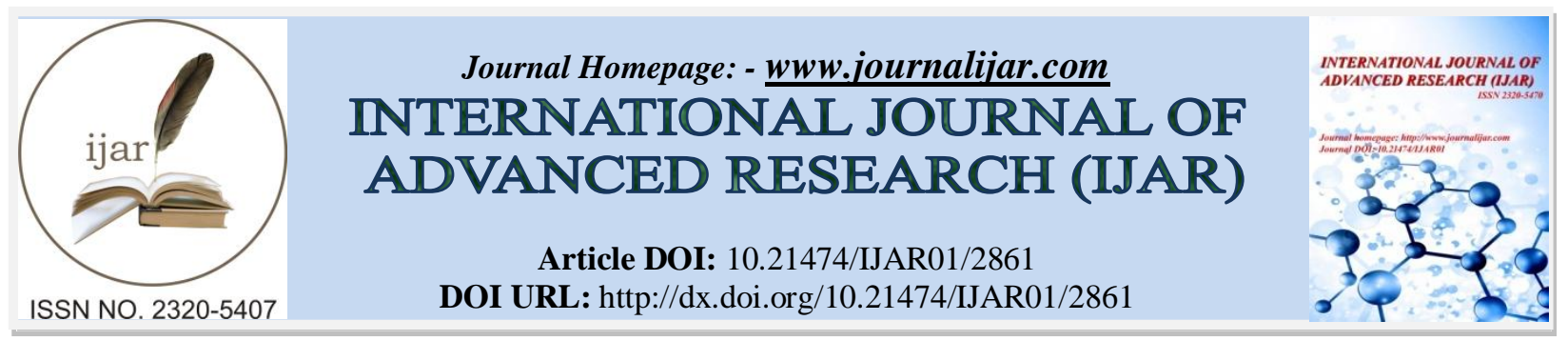

RESEARCH ARTICLE

\title{
BIG FIVE PERSONALITY AND PSYCHOLOGICAL CAPITAL AMONG FINAL YEAR MEDICAL STUDENTS.
}

\section{Evelyn Raghel Thomas ${ }^{1}$ and GeetikaTankha ${ }^{2}$.}

1. Research Scholar, Department of Psychology, Manipal University Jaipur, Rajasthan, India.

2. Professor, Department of Psychology, Manipal University Jaipur, Rajasthan, India.

\section{Manuscript Info} ..........................

\section{Manuscript History}

Received: 21 November 2016

Final Accepted: 21 December 2016

Published: January 2017

\section{Key words:-}

Psychological Capital (PsyCap), Hope, Efficacy, Optimism, Resilience, Big Five, Medical students, Agreeableness, Extraversion

\section{Abstract}

The performance of medical students is influenced by both personality characteristics and positive psychological capital. The aim of the current study was to examine the relationship between Big Five Personality traits and PsyCap among final year medical students and secondly, to determine whether Big Five personality traits hold predictive value for PsyCapof final year medical students. Participants for this study were 200 (90 males and 110 females) final year MBBS students pursuing their course in a Government Medical College of Jaipur City. PCQ-24(Luthans, Avolio and Avey, 2007) and Big Five Inventory (John \&Srivastava, 1999) were used to measure PsyCap and personality traits respectively. Results of bivariate associations showed that overall measure of psychological capital(PsyCap) was significantly related to all of the personality traits, except for conscientiousness. By means of multiple regression analysis, the findings revealed that Extraversion and Agreeableness were significant predictors of PsyCap. Implications of these findings are discussed.

Copy Right, IJAR, 2016,. All rights reserved.

\section{Introduction:-}

The study of medicine is a long and laborious process of five and a half years. The personality and psychological capital strength of medical students is an important determinant of their successful accomplishment of the course. The prevalence of anxiety, depression and burnout increases during their graduation program. Numerous studies have examined potential risk factors that pose a threat to students' mental health. These potential risk factors are workload, competition, sleep deprivation, lack of social support and the suffering and dying of patients which contribute to medical students' stress and their deteriorating mental health. One of the important steps would be identifying positive human resources such as hope, resilience, self - efficacy, optimism, hardiness, sense of coherence and personality factors such as agreeableness, conscientiousness, openness etc. in medical students to promote good health. The ability to solve problem, critical thinking, strong communication skills and integrity are some of the important factors in medical training followed by residency and professionalism. As a positive psychological resource, PsyCap tends to improve academic performance as well as contributes to personality development in medical students. Big five factors i.e. Extraversion, Openness to experience, Conscientiousness, Neuroticism and Agreeableness, success, adjustment, physical as well as psychological health are important in ensuring their suitability for medical schools since they are future doctors. Therefore, there is an important need to 
assess the personality and psychological capital strength of Indian medical students as there is a dearth of research done on this aspect. Medical students have to balance the pressure of academics and clinical experience.

Hence, the objective of this study is to assess the big five factors and PsyCap in Final Year MBBS students and further explore the relationship between Big Five Personality factors and components of PsyCap.

Psychological Capital (PsyCap) is defined as study and application of positively oriented human resource strength and psychological capacities (Luthans\& Youssef, 2004). In terms of positive organizational behaviour, PsyCap acts as interventional model for employees and organization. PsyCap consists of four state-like psychological resource capacities of self-efficacy, hope, optimism and resilience which are measurable and open to development. Self efficacy is defined as individual's positive belief about one's ability when confronted with difficult tasks. Hope refers to positive motivational state strengthening individual's perseverance in the path of desired goal and success. Resilience is identified as bouncing back in the time of adversity or positive state that goes beyond failure to attain success. Optimism refers to positive aspect regarding self - attribution towards goal achievement (Luthans, Avolio, Avey\& Norman, 2007).

The Big Five personality traits are five broad domains or dimensions of personality that are used to describe human personality, the five-factor model.Openness to experience refers toAppreciation for art, emotion, adventure, unusual ideas, curiosity, and variety of experience. Conscientiousness refers to tendency to be organized and dependable, show self-discipline, act dutifully, aim for achievement, and prefer planned rather than spontaneous behaviour.Extraversion refers to Energy, positive emotions, assertiveness, sociability and the tendency to seek stimulationfrom others. Neuroticism refers to the tendency to experience unpleasant emotions easily, such as anger, anxiety, depression, and vulnerability.

Researchers have shown that performance of both Malaysian medical students and doctors is influenced by certain personality traits such as agreeableness, openness and conscientiousness. There was a positive significant association of agreeableness, openness and conscientiousness with respect to academic achievement in a cross sectional study of medical students studying in seven universities. Furthermore, significant gender differences were reported in which females scored high in openness, agreeableness and conscientiousness as compared to males (Mustaffa et al., 2012).

Personality traits such as conscientiousness denote learning habits that are considered to be favourable to academic achievements, namely hardworking, responsible, and self-discipline (ChamorroPremuzic\&Furnham, 2003a; Chamorro Premuzic\&Furnham, 2003b; Gray\& Watson, 2002; Laidra et al., 2007 ; Lieven et al., 2002;Noftle\& Robins, 2007).A study by Mirsaleh et al. (2010) showed that there was a positive correlation between openness and conscientiousness in medical students and negative correlation between neuroticism and satisfaction with clinical training.Klasner and Pistole(2003) discovered the influence of personality and social support in adjustment process in medical students. The big five factors except neuroticism significantly associated with mental health, coping and academic stress.

In terms of academic achievement in medical school, Ferguson et al. (2000) and Lievens et al. (2002) found that conscientiousness is a significant predictor of academic success.Studies on success in medical studies and personality have reported that high scores in conscientiousness and low scores in neuroticism are associated with success (Barrick \& Mount, 1991; Salgado, 1997). Tanoff (1999) through his research concluded that neuroticism is a primary factor, in determining job satisfaction. Further, Connolly and Viswesvaran (2000) asserted that neuroticism was negatively associated with job performance among employees.

Openness to experience has been found to significantly correlate with academic achievement in medical students. Further, poor personality traits and negative coping styles appear to play a role in the physical and psychological health of medical students (Wang \& Miao, 2009).

Multon, Brown and Lent (1991) concluded their meta-analysis and found academic self-efficacy is more predictive than general self-efficacy in educational context. Besides, researchers also conducted academic resilience scales in educational studies (Martin \& Marsh, 2006). Therefore, this study re-combined the four components of PsyCap for educational application with academic self-efficacy, optimism, hope, and academic resilience. 
A study by Khan et al. (2011) among undergraduate students of different universities of Kuala Lumpur concludedthat positivepsychological capital and big five personality traits werefound to be significantly related to coping mechanisms exceptneuroticism. High extraversion, openness \& conscientiousnessindividuals engaged in more problem-focused coping. Therefore, personality factors and positivepsychological capital has emerged as important constructs fordetecting coping mechanisms.

In Indian context, there is a dearth of research on PsyCap in medical students, henceforth, in the light of above concerns, the present study aims to examine big five personality factors and PsyCap in Final Year MBBS students and further investigate the relationship between PsyCap (i.e. Hope, Resilience, Optimism and Efficacy) and big five personality traits (i.e. Extraversion, Openness to experience, Conscientiousness, Neuroticism and Agreeableness) in medical students.

\section{Methods:-}

Sample:-

This study comprised of 200 (90 males and 110 females) final year MBBS students studying in SMS medical college in Jaipur, Rajasthan in the age range of (20-25 years) and their mean age is 23.19 years.

\section{Materials:-}

\section{Proforma:-}

Information about the demographic details such as age, gender, year of study, etc.were obtained from each student who participated in the survey

Psychological Capital Questionnaire(Luthans, Youssef \&Avolio, 2007) - PCQ was developed by Luthans, Avey and Avolio in 2007. It measures PsyCap and comprises four subscales, namely, hope, optimism, resilience and self efficacy. The PCQ is a self - report 24 item questionnaire. Each subscale is comprised of six items and assessed on a six-point Likert scale with the response options: 1 - strongly disagree, 2 - disagree, 3 - somewhat disagree, 4 somewhat agree, 5 - agree, 6 - strongly agree. The resulting score represents an individual's level of PsyCap.

Big Five Inventory(John \&Srivastava, 1999) - BFI was developed by John and Srivastava in 1999. It measures big five personality traits namely extraversion, conscientiousness, Neuroticism, Openness and Agreeableness. The BFI is a self - report questionnaire and has 44 item measured on a 5- point Likert scale ranging from 1(Strongly disagree) to 5(strongly agree). Alpha reliabilities were reported as follows: .87 for Extraversion, .79 for agreeableness, .81 for Conscientiousness, .82 for Neuroticism and .79 for Openness to Experience.

\section{Procedure:-}

Participants were recruited from MBBS section of Government medical college. PsyCap questionnaire and Big Five Personality Inventory were administered among 200 respondents in their medical college. Demographic information was collected through questionnaires. Instructions were given to the respondents before administration of the scale. For data analysis, SPSS version 21 was used for descriptive analysis (mean, standard deviation) of the data. Pearson Product Moment Correlation was used to investigate the relationship of PsyCapto Big Five Personality factors, furthermore,hierarchical multiple regression analysis was used to identify significant predictors of PsyCap and its components.

\section{Results:-}

Table 1 lists the means and standard deviations of the study variables, as well as the partial correlations between these variables. These bivariate associations show that the overall measure of psychological capital(PsyCap) was significantly related to all of the personality traits, except for conscientiousness. The means regarding PsyCap and its components i.e. hope, resilience, efficacy and optimism of final year medical students were 4.47, 4.61, 4.25, 4.68 and 4.32 respectively. These means indicate higher levels of self - efficacy and hope and average level of overall PsyCap, Resilience and optimism. Table 1 also indicates that among the five personality factors (i.e. Openness to experience, Conscientiousness, Extraversion, Agreeableness and Neuroticism), Overall PsyCap has significant positive association with Agreeableness $(.358, \mathrm{p}<.01)$ and Extraversion $(-.214, \mathrm{p}<.05)$. Furthermore, the components of PsyCap were also significantly associated with big five factors of personality. Hope was significantly associated with Agreeableness $(.202, \mathrm{p}<.01)$ and negatively associated with Neuroticism $(-431, \mathrm{p}<.05)$. Efficacy had significant positive relationship with Extraversion (.244, p >.01), Agreeableness (.260, $p$ <.05) and Neuroticism 
$(-.432, \mathrm{p}<.05)$. Similarly, Resilience had significant positive correlation with Agreeableness $(.307, \mathrm{p}<.05)$ and Extraversion (.228. $\mathrm{p}<.01)$. Optimism was significantly associated with Agreeableness $(.439, \mathrm{p}<.05)$, Conscientiousness $(.201, \mathrm{p}<.01)$ and openness to experience $(.326, \mathrm{p}<.05$. $)$.

By means of hierarchical linear regression analysis, significant linear relationships were identified between big five personality factors and overall PsyCap. Table 2 clearly indicates that Extraversion $(\beta-.382, \mathrm{t}-3.858, \mathrm{p}-.000)$ and Agreeableness $(\beta-.449, \mathrm{t}-6.390, \mathrm{p}-.000)$ were significant predictors of PsyCap, $\mathrm{F}(5,194)=13.745(\mathrm{p}<.000)$.

Table 1:- Means, Standard Deviations and Partial Correlations of the study variables.

\begin{tabular}{|l|l|l|l|l|l|l|l|l|l|l|l|l|}
\hline & Mean & S.D & 1 & 2 & 3 & 4 & 5 & 6 & 7 & 8 & 9 & 10 \\
\hline 1.PsyCap & 4.47 & .49 & 1 & $.72^{* *}$ & $.83^{* *}$ & $.77^{* *}$ & $.79^{* *}$ & $.36^{* *}$ & .11 & $.21^{* *}$ & $-.26^{* *}$ & $.17^{*}$ \\
\hline 2.Hope & 4.61 & .58 & & 1 & $.64^{* *}$ & $.34^{* *}$ & $.30^{* *}$ & $.15^{*}$ & .01 & $.21^{* *}$ & $-.47^{* *}$ & $.15^{*}$ \\
\hline 3.Efficacy & 4.68 & .63 & & & 1 & $.53^{* *}$ & $.57^{* *}$ & $.29^{* *}$ & $.14^{*}$ & $.27^{* *}$ & $-.42^{* *}$ & .00 \\
\hline 4.Resilience & 4.25 & .68 & & & & 1 & $.61^{* *}$ & $.31^{* *}$ & .05 & $.25^{* *}$ & .04 & .10 \\
\hline 5.Optimism & 4.32 & .58 & & & & & 1 & $.43^{* *}$ & $.16^{*}$ & -.05 & -.00 & $.28^{* *}$ \\
\hline 6.Agreeableness & 3.69 & .54 & & & & & & 1 & $.55^{* *}$ & $.19^{* *}$ & $-.25^{* *}$ & .14 \\
\hline 7.Conscietousness & 3.58 & .60 & & & & & & & 1 & -.04 &.$- .42^{* *}$ & $.16^{*}$ \\
\hline 8.Extraversion & 3.25 & .36 & & & & & & & & 1 & $-.38^{* *}$ & -.07 \\
\hline 9.Neuroticism & 2.90 & .68 & & & & & & & & & 1 & $-.18^{* *}$ \\
\hline 10.Openness & 4.32 & .58 & & & & & & & & & & 1 \\
\hline
\end{tabular}

Note $-* \mathrm{p}<.01$

Table 2:- The results of Hierarchical Linear Regression Analysis.

\begin{tabular}{|c|c|c|c|}
\hline Variables & Step $1(\beta)$ & Step $2(\beta)$ & Step 3( $\beta)$ \\
\hline \multicolumn{4}{|l|}{ Step 1} \\
\hline Age & 0.156 & .103 & .093 \\
\hline Gender & $-.138 * *$ & $-.108 * *$ & $-.087 * *$ \\
\hline \multicolumn{4}{|l|}{ Step 2} \\
\hline Opennessto Experience & & .136 & .221 \\
\hline Conscientiousness & & -.212 & -.176 \\
\hline Extraversion & & .277 & $.382 * *$ \\
\hline Agreeableness & & .490 & $.449 * *$ \\
\hline Neuroticism & & -.097 & -.071 \\
\hline \multicolumn{4}{|l|}{ Step 3} \\
\hline Psychological Capital & & & $.243 * *$ \\
\hline $\mathrm{F}$ & $13.745 * *$ & $36.665 * *$ & $49.657 * *$ \\
\hline $\mathrm{R}^{2}$ & .262 & .213 & .511 \\
\hline$\Delta \mathrm{R}^{2}$ & .243 & .339 & .051 \\
\hline
\end{tabular}

Note $-* \mathrm{p}<.01$

\section{Discussion:-}

The main objective of this study was to explore the relationship between PsyCap and Big Five Factors of Personality among Final year MBBS students. On the basis of relationship between PsyCap and Personality factors, it was observed that the facets of PsyCap namely Hope, Efficacy, Optimism and Resilience are significantly associated with Agreeableness, Neuroticism, Extraversion, Conscientiousness and Openness to Experiences. This demonstrates that medical students high on traits such as Agreeableness and Extraversion tends to have stronger PsyCap levels.People who arehigh in this trait tend to exhibit positive experiences in socialsituations and are helpful, cooperative, caring and being affectionate .In comparison to other non - medical streams like engineering, law, mass media and architecture, the personality domains vary from person to person.

With respect to components of PsyCap, this study shows that the medical students have higher levels of Hope and Efficacy which indicates that they are persistent in goal attainment in academics as well as clinical practise. Similar findings were reported in meta-analytic study by Multon(1991) on PsyCap as a predictor of Academic performance in different educational contexts. With respect to the five personality factors, Agreeableness is having significant positive relationship with overall PsyCap and components of PsyCap, i.e. Hope, Efficacy and Optimism 
respectively. Agreeableness trait has an interpersonal dimension which means that medical students are empathetic andlike to help others (Costa \& McCrae, 1992).

Results also showed that Neuroticism has scored lowest in medical students and is having significant relationship with overall Psycap as well as four facets of PsyCap. In a comparative study by Mustaffa et al. (2012), similar results were observed in which personality traits were examined based on year of the study of MBBS students and Fifth year students scored lowest on neuroticism as compared to first, second, third and fourth year students. In this regard, low scores on Neuroticism implies that fifth year students were more emotionally stable and less impulsive.

In addition, it can be is a very good development since medical doctors need to not only deal withpatients but also their families and the general public. It is very important for the doctors to always be verycareful, patient, and able to control their emotions especially when faced with critical and crisis situations. They alsoneed to be calm and have strong coping abilities.

The limitation of this studyis that the data are based on subjective evaluations of final year medical students and due to uneven sample ratio of gender i.e. Male $(70 \%)$ and Female(30\%), gender differences was not investigated with respect to personality traits and PsyCap.

This study indicates the need to investigate predictors with respect to PsyCap and Personality traits in medical students using Regression Analysis and identify positive psychological resources in different groups of Non Medical streams in view of promoting stress management, mental health promoting programs among students.

\section{Conclusion:-}

The results of this study revealed significant associations of Agreeableness and Extraversion with overallPsyCap in final year medical students. It is concluded by analysing various literatures that, fewstudies have investigated the relationship between both big five personality factors and PsyCap for training and interventional aspect that would be helpful in medical training and clinical experience as doctors. Especially in medicine sector, the examination of positive psychological capacities with Big Five Personality dimension will lead to better understanding of medical profession and the basic personality profile will help them choose their specialisation and foster their professional life.

\section{References:-}

1. Barrick, M. R., \& Mount, M. K. (1991). The big five personality dimensions and job performance: a meta-analysis. Personnel Psychology, 44(1), 1-26.

2. Chamorro-Premuzic, T., \&Furnham, A.(2003a). Personality traits and academic examination performance. European Journal of Personality, 17(3), 237 - 250.

3. Chamorro-Premuzic, T., \&Furnham, A. (2003b). Personality predicts academic performance:Evidence from two longitudinal university samples. Journal of Research in Personality,37(4), 319-338.

4. Connolly, J. J., \&Viswesvaran, C. (2000). The role of affectivity in job satisfaction: A metaanalysis. Personality and Individual Differences, 29(2), 265-281.

5. Costa, P. T., \& McCrae, R. R. (1992). Four ways five factors are basic. Personality and Individual Differences, 13(6), 653-665.

6. Farsides, T., \& Woodfield, R. (2003). Individual differences and undergraduate academic success: The roles ofpersonality, intelligence and application. Personality and Individual Differences, 34(7), 1225-1243.

7. Ferguson, E., Sanders, A., O'Hehir, F., \& James, D. (2000). Predictive validity of personal statements and therole of the five-factor model of personality in relation to medical training. Journal of Occupational andOrganizational Psychology,73(1),321-344.

8. Ferguson, F., Payne, T., \& Anderson, N. (1994). Occupational personality assessment. Theory, structure andpsychometrics of the OPQ FMX-5 student. Personality and Individual Differences, 17(1), 217-225.

9. Gray, E. K., \& Watson, D. (2002). General and specific traits of personality and their relation to sleep and academic performance. Journal of Personality, 70(2), 177-206.

10. John, O. P., \&Srivastava, S. (1999). The Big Five trait taxonomy: History, measurement, and theoretical perspectives. Handbook of personality: Theory and research,2, 102-138. 
11. Khan, A., Siraj, S., \& Li, L. P. (2011).Role of positive psychological strengths and big five personality traits in coping mechanism of university students. In International Conference on Humanities, Society and Culture (Vol. 20, pp. 210-215).

12. Klasner, L., \&Pistole, M. C. (2003). College adjustment in a multiethnic sample: Attachment,separationindividuation, and ethnic identity. Journal of College Student Development, 44(1), 92-109.

13. Laidra, K., Pullmann, H., \&Allik, J. (2007). Personality and intelligence as predictors of academic achievement: A cross-sectional study from elementary to secondary school. Personality and Individual Differences, 42(3), 441-451.

14. Lievens, F., Coetsier, P., De- Fruyt, F., \& De Maeseneer, J. (2002). Medical students' personality characteristicsand academic performance: A five-factor model perspective. Medical Education, 36(11), 10501056.

15. Luthans, F., Avolio, B. J., Avey, J. B., \& Norman, S. M. (2007). Positive psychological capital: Measurement and relationship with performance and satisfaction. Personnel Psychology, 60(3), 541-572.

16. Luthans, F., \& Youssef, C. M. (2004). Human, social, and now positive psychological capital management:: Investing in people for competitive advantage. Organizational dynamics, 33(2), 143-160.

17. Martin, A. J., \& Marsh, H. W. (2006). Academic resilience and its psychological and educational correlates: A construct validity approach. Psychology in the Schools, 43(3), 267-281.

18. Mirsaleh, Y. R., Tabatabaee, A., Rezai, Kivi, S.R., \&Ghorbani, R. (2010). The role of religiosity, copingstrategies, self-efficacy and personality dimensions in the prediction of Iranian undergraduate rehabilitationinterns' satisfaction with their clinical experience. Clinical Rehabilitation, 24(12), 1136-1143.

19. Multon, K. D., Brown, S. D., \& Lent, R. W. (1991). Relation of self-efficacy beliefs to academic outcomes: A meta-analytic investigation. Journal of Counseling Psychology, 38(1), 30.

20. Mustaffa, M. B., Wan Shahrazad, W.S., Khairudin, R., \& Syed Salim, S. S. (2012). Parental support,personality, self-efficacy as predictors for depression among medical students. Pertanika Journal of SocialSciences \& Humanities, 19(4), 9-15.

21. Noftle, E. E., \& Robins, R. W. (2007). Personality predictors of academic outcomes: big five correlates of GPA and SAT scores. Journal of Personality and Social Psychology, 93(1), 116.

22. Radcliffe, C., \& Lester, H. (2003). Perceived stress during undergraduate medical training: A qualitative study.Medical Education, 37(1), 32-38.

23. Salgado, J. F. (1997). The five factor model of personality and job performance in the European community.Journal of Applied Psychology, 82(1), 30-43.

24. Tanoff, G. F. (1999). Job satisfaction and personality: The utility of the Five-Factor Model of Personality (Doctoral dissertation, ProQuest Information \& Learning).

25. Wang, W., \& Miao, D. (2009). The relationship among coping styles, personality traits and mental health ofChinese medical students. Social Behaviour and Personality, 37(2), 163-172. 